\title{
TECNOLOGIA ASSISTIVA EM SAÚDE PARA CEGOS: ENFOQUE NA PREVENÇÃO DE DROGAS ${ }^{a}$
}

\author{
Assistive Health Technology for the Blind People: \\ AFocus on Drugs Prevention \\ Tecnología Asistiva en Salud para Ciegos: \\ Enfoque en la Prevención de Drogas
}

Kariane Gomes Cezario ${ }^{1}$

Lorita Marlena Freitag Pagliuca²

\section{Resumo}

Diante da nocividade das drogas aos indivíduos e da vulnerabilidade dos cegos a elas, em virtude de condições favoráveis, objetivou-se desenvolver e avaliar Tecnologia Assistiva em Saúde, acessível a esta clientela. Estudo de desenvolvimento e avaliação de Tecnologia Assistiva em Saúde, sobre a prevenção ao uso de drogas entre cegos, realizado em uma associação de cegos, em Fortaleza, em abril de 2007. Participaram cinco homens, que apreciaram o recurso tecnológico constituído do texto educativo Drogas: Reflexão para prevenção, utilizado em programa de computador de síntese de voz (Dosvox). Seu conteúdo abordou os principais tipos de drogas, efeitos físicos, psicológicos e sociais, além de meios de prevenção. Fez-se avaliação por meio de depoimentos. A Tecnologia Assistiva foi considerada informativa, satisfatória e alcançou 0 objetivo proposto. Neste tipo de recurso, a educação em saúde foi vista como válida.

Palavras-chave: Drogas llícitas. Tecnologia. Educação em Saúde. Portadores de Deficiência Visual.

\begin{abstract}
In view of the noxiousness of drugs to individuals and blind people's vulnerability to them, due to favorable conditions, this study aimed to develop and assess Assistive Health Technology accessible to these clients. Development and assessment study of Assistive Health Technology, about the prevention of drugs use among blind people, carried out at an association of blind people in Fortaleza, Brazil, in April 2007. Participants were five men who assessed the technological resource, which consisted of the educational text Drugs: Reflection for prevention, used in a voice synthesis computer program (Dosvox). Its content addressed the main kinds of drugs; physical, psychological and social effects; besides prevention means. Assessments were made through testimonies. The Assistive Technology was considered informative, satisfactory and reached its objective. In this type of resource, health education was seen as valid.
\end{abstract}

Keywords: Street Drugs. Technology. Health Education. Visually Impaired Persons.

\section{Resumen}

Ante la nocividad de las drogas a los individuos y la vulnerabilidad de los ciegos a ellas, en virtud de condiciones favorables, la finalidad fue desarrollar y evaluar tecnología asistiva en salud, accesible a esta clientela. Estudio de desarrollo y evaluación de Tecnología Asistiva en Salud, sobre la prevención del uso de drogas entre ciegos, realizado en una asociación de ciegos, en Fortaleza, Brasil, en abril de 2007. Participaron cinco hombres, que apreciaron el recurso tecnológico, que constituyó del texto educativo Drogas: Reflexión para prevención, utilizado en programa de computadora, de síntesis de voz (Dosvox). Su contenido aborda los principales tipos de drogas; sus efectos físicos, psicológicos, e sociales; además de medios de prevención. La evaluación se efectuó mediante testimonios. La Tecnología Asistiva fue considerada informativa, satisfactoria y alcanzó el objetivo a que se propone. En este tipo de recurso, la educación en salud se consideró como válida.

Palabras clave: Drogas llícitas. Tecnología. Educación en Salud. Personas con Daño Visual. 


\section{INTRODUÇÃO}

As drogas, chamadas substâncias psicotrópicas ou psicoativas, são nocivas ao organismo e alteram seu funcionamento principalmente no nível do sistema nervoso centrall. Representam, pois, um malefício na vida dos usuários, por provocarem desestruturação fisiológica, psicológica e nas relações interpessoais.

Como se sabe, os cegos possuem as mesmas características de desenvolvimento que as demais pessoas. Desse modo, são também vulneráveis às drogas. Embora lhes falte a visão, isto não impede a convivência com diferentes grupos sociais, e a curiosidade de experimentar situações novas, pelo contrário, poderá até exacerbá-la. Qualquer indivíduo, diante de condições favoráveis, poderá desenvolver algum vício ou dependência². Portanto, o uso das drogas independe de raça, cor, faixa etária ou nível econômico, ou seja, todos os indivíduos são vulneráveis.

De modo geral, a sociedade convive com o consumo e abuso de drogas e se preocupa com esta situação. Especificamente os profissionais de saúde, em decorrência da própria formação, sabem das graves conseqüências passíveis de advir com o uso destas, tais como: malefícios para o indivíduo e seu meio social, prejuízo biológico causado ao usuário, por se tratar de um problema de saúde pública e por gerar a marginalização do usuário perante a sociedade.

Estudo monográfico anterior mostrou que os cegos têm conhecimento precário sobre o tema drogas. Contudo, experiências e expectativas acerca da problemática estão presentes nesta clientela, o que justifica o desenvolvimento de ações dirigidas à prevenção? ${ }^{3}$.

Como parte das suas responsabilidades, cabe aos profissionais de saúde, além do fazer técnico, desenvolver estratégias de promoção e manutenção da saúde, por meio de medidas preventivas adequadas à população $0^{4}$. Neste cenário, destaca-se o papel do enfermeiro como profissional capacitado para atuar em relação à problemática droga, seja no contexto da prevenção, mediante educação em saúde, seja no acompanhamento de usuários, pela participação no tratamento e reabilitação ${ }^{5}$.

Entre as estratégias possíveis no enfrentamento a este problema, está a criação de Tecnologia Assistiva (TA), entendida como todos os recursos e serviços que contribuem para proporcionar ou ampliar habilidades funcionais de pessoas com deficiênciae assim promovervidaindependentee indusão. Seus objetivos principais são gerar acessibilidade, qualidade de vida e inclusão, pois proporciona maiores possibilidades de independência, locomoção, educação, saúde, entre outros aspectos ${ }^{6}$.

Considerando a clientela objeto do nosso interesse, constituem-se recursos todos os materiais utilizados e adaptados ao cego e ao deficiente visual, entre eles a bengala, brinquedos, softwares, termômetro, entre outros. Por sua vez, os serviços traduzem-se na assistência profissional à pessoa com deficiência em que se seleciona, desenvolve ou utiliza uma Tecnologia Assistiva ${ }^{6}$. A Enfermagem presta assistência profissional a esta parcela da população e, para tornar sua assistência acessível, cria recursos tecnológicos, portanto apóia-se no suporte da Tecnologia Assistiva nos seus dois aspectos: cria recursos e presta serviço.

Ao se observarem os programas de combate às drogas, estes utilizam predominantemente papel e tinta ou imagens televisivas; deste modo, privam o cego do acesso à informação. Contudo, os cegos possuem algum conhecimento acerca das drogas. Este, porém, é limitado, pois reinterpretar uma comunicação elaborada por e para videntes raramente obtém pleno êxito visto que os elementos de elaboração do conhecimento são outros ${ }^{7}$. Basicamente, a comunicação com o cego se processa mediante utilização da audição e do tato. Por conseguinte, os materiais preparados e adaptados para estas pessoas devem possuir estas características.

Os cegos contam, atualmente, com variados recursos que auxiliam em seu processo de apreensão e aprendizagem dos principais conteúdos do conhecimento: materiais adaptados, Livro Falado, Sistema de Leitura Ampliada, Thermoform. Além disso, nos microcomputadores acessíveis, existe o Terminal Braille, Impressora Braille, Scanner de Mesa e, especialmente, os Sintetizadores de Voz, com destaque para o Sistema Operacional Dosvox, cuja grande aceitação pelos usuários, tanto em nível domiciliar quanto em nível escolar, tornou-o um dos mais utilizados em todo o país.

0 Dosvox destina-se a auxiliar os cegos a utilizar o computador, executando tarefas como edição de textos, leitura/ audição de textos anteriormente transcritos, além da utilização de ferramentas de produtividade faladas. Como ferramenta na educação, proporciona formação cultural e tecnológica, permite acesso à leitura, ao domínio do computador e à aldeia global. Assim, para uma maior efetividade deste recurso, demandam-se ações que possam difundi-lo entre o maior número possível de usuários ${ }^{9}$.

Segundo evidenciado, estudos sobre o uso de drogas por cegos são escassos. Diante disto, e com base na importância da prevenção da dependência, objetivou-se desenvolver e avaliar a Tecnologia Assistiva em Saúde, informando sobre os malefícios do uso de drogas com o intuito de gerar reflexões e prevenção.

\section{METODOLOGIA}

Trata-se de um estudo de desenvolvimento e avaliação de Tecnologia Assistiva em Saúde, sobre a prevenção ao uso de drogas entre cegos. Estudos deste tipo têm como finalidade desenvolver recursos e serviços que contribuam para promover vida independente e inclusão de pessoas portadoras de deficiência. Nesta perspectiva, o recurso desenvolvido foi um material educativo sobre drogas, preparado em meio digital, e o serviço foi a utilização deste material por sujeitos cegos. 0 trabalho desenvolveu-se durante o período de fevereiro a abril de 2007.

Entre fevereiro e março de 2007, foi criado o recurso tecnológico. Realizou-se pesquisa bibliográfica nas bases de dados Scielo e Bireme, além do site Google Acadêmico, com a finalidade de obter materiais e artigos científicos, com publicação situada entre 1997 e 2007.0 material coletado trouxe embasamento acerca da temática droga, e, após leitura atenta, os artigos foram fichados, fez-se a organização do índice de assuntos e, em seguida, procedeu-se à redação do texto, com vistas a atribuir ao discurso um caráter reflexivo e dialogal que permitisse maior aproximação entre o usuário e a tecnologia.

A pesquisadora participou de treinamento para utilização do Dosvox, tendo como facilitadora desta etapa uma usuária 
experiente do programa, cuja participação na pesquisa restringiu-se a esta etapa. Finalmente, instalou-se o Dosvox no computador portátil disponível para o trabalho e converteuse o material produzido para arquivo acessível ao programa.

Para a etapa de serviço, que compreende a fase da assistência no desenvolvimento de Tecnologia Assistiva, solicitou-se o consentimento da Associação de Cegos do Estado do Ceará (ACEC) e, logo após, enviou-se o projeto ao Comitê de Ética e Pesquisa do Complexo Hospitalar da Universidade Federal do Ceará, que o aprovou, sob o protocolo n 126/06. Foram respeitadas as orientações para a pesquisa envolvendo seres humanos, conforme Resolução 196/96 do CNS, destacando-se respeito ao anonimato, não maleficência, direito de afastar-se da pesquisa a qualquer momento e acompanhar seus resultados. Providenciou-se, então, o termo de consentimento livre e esclarecido dos sujeitos, o qual foi lido e explicado pela pesquisadora e, em seguida, assinado por cada participante e, também, por uma testemunha vidente.

A fase de assistência ocorreu em abril de 2007 e teve como sujeitos homens cegos, sem restrição de idade. A opção pelo sexo masculino foi intencional já que o grupo feminino foi abordado em um outro estudo. Ao expressarem interesse em participar do trabalho, após convite aber to entre membros da ACEC, os participantes e a pesquisadora se encontravam. Neste momento era disponibilizado o recurso eletrônico contendo texto sobre droga em sala reservada. 0 cego procedeu à escuta atenta e interação com o recurso tecnológico, com a pesquisadora atuando como facilitadora em caso de dúvidas sobre o texto ou de dificuldades em manusear o computador, atuando assim na fase de assistência da tecnologia.

Para a avaliação da Tecnologia Assistiva, o participante foi convidado a responder às seguintes perguntas: Qual sua opinião em relação ao conteúdo do texto? Em relação ao tempo de execução? 0 que você teria a acrescentar ao texto? 0 que você teria a retirar do texto? Qual sua opinião em relação à educação em saúde utilizando o Dosvox? Estas entrevistas foram gravadas com consentimento do sujeito, posteriormente transcritas e organizadas na seqüência das questões, sendo selecionados trechos das falas que expressavam juízo de valor favorável e desfavorável quanto ao recurso tecnológico apreciado. Não foi avaliada a fase de assistência da tecnologia, pois se pretende que na sua finalização este seja um recurso auto-instrucional, dispensando a presença da enfermeira.

0 número de participantes foi estabelecido por saturação, que consiste em um processo de coleta de dados a ponto de se obter uma sensação de encerramento, porque os dados novos trazem informações repetidas ${ }^{10}$.

\section{RESULTADOS E DISCUSSÃO}

A Tecnologia Assistiva em Saúde compôs-se da criação de um recurso tecnológico, um texto denominado Drogas: Reflexão para prevenção, com abordagem reflexiva e dialogal sobre as drogas, seus principais tipos, efeitos físicos, psicológicos e sociais, além de meios de prevenção. Este texto foi disponibilizado por programa de computador específico para a clientela cega, chamado Dosvox, que transforma o texto digitado em síntese de voz, para, deste modo, tornar acessível seu conteúdo aos cegos.

Sua avaliação contou com a participação de cinco homens cegos, na faixa etária entre 17 e 37 anos. Após contato com a referida tecnologia, procederam à sua avaliação, respondendo aos questionamentos da pesquisadora no referente ao conteúdo do texto em geral e ao método em si. A seguir, expõem-se os resultados em categorias conforme depoimento dos participantes.

Em relação ao conteúdo do texto:

Os participantes avaliaram o conteúdo do texto como abrangente e completo nos pontos destinados a abordar: família, prevenção, tipos de usuário de substâncias, principais drogas e seus aspectos mais relevantes. Pelo caráter dialogal e reflexivo do texto, segundo um dos depoimentos, era como se estivesse vivenciando cada etapa percorrida pela narrativa. Apesar de quase todos os depoimentos afirmarem que 0 conteúdo estava plenamente satisfatório, um deles sugeriu uma exploração mais pormenorizada dos aspectos relativos diretamente às drogas em detrimento dos aspectos familiares e sociais.

[...] o texto realmente foi completo, de uma amplitude muito grande. $(P 1)$

[...] acho que deveria resumir essa parte da família e explorar mais a parte das drogas em si. Essa parte todo mundo já sabe e a outra não. (P2)

[...] senti como se tivesse vivendo cada momento, passando por aquilo. Simplesmente achei interessante. (P3)

Ao desenvolver o texto, com linguagem que se aproxima do diálogo e gera reflexões, procurou-se valorizar a premissa de que, no processo de interação com o cego, um dos pontos mais relevantes é a comunicação verbal, e esta deve estruturar-se na busca contínua do diálogo. Tal estratégia deve existir em todos os âmbitos da interação, incluindo-se o processo de ensino-aprendizagem, a exemplo da educação em saúde na prevenção do uso de drogas ${ }^{11}$.

Outro ponto extremamente importante nessa abordagem é a delimitação do conteúdo, o qual deve contemplar, na magnitude dos conhecimentos necessários à abordagem desta problemática, os efeitos, dosagens, danos, formas de utilização, compreensão dos motivos que levam ao uso, formas de tratamento, fatores de risco e proteção, populações de risco e políticas públicas ${ }^{12}$. Complementa-se esta linha de conteúdo enfatizando também o uso de drogas e as relações familiares e afetivas, DST/AIDS e aspectos pessoais/psicológicos do usuário ou potencial usuário ${ }^{13}$.

Por fim, considera-se relevante fornecer informações que diferenciem o consumo devido do indevido de substâncias, as drogas lícitas das ilícitas, os diferentes tipos de usuários, além de outros aspectos cabíveis à temática. Este tipo de informação abre espaço para um debate crítico e construtivo sobre a amplitude deste problema ${ }^{13}$.

\section{Em relação ao tempo de execução:}

Os participantes consideraram o tempo do recurso tecnológico satisfatório, diante das características particulares de reprodução das falas do Dosvox, que naturalmente torna o período de reprodução um pouco maior. Apenas um depoente opinou que o tempo está além do desejável, e recomendou a 
diminuição do texto para uma reprodução mais objetiva. Contudo, tal afirmativa não foi corroborada pelos demais participantes.

Foi o ideal. (P1)

[...] eu tô achando longo. (P2)

[...] as pessoas com deficiência visual, às vezes, têm o raciocínio um pouco mais lento, principalmente quando ela já nasce assim. Ela vai adquirindo lentamente $o$ poder de usar a mente, rapidez, pra eles vai ser ótimo ser lento.(P3)

Como proposto por determinados autores, a construção de recursos educacionais acessíveis aos cegos, e aqui se inclui a educação em saúde, deve seguir algumas condições características desta clientela, como: atentar para as limitações de contato do cego com o ambiente físico onde este é inserido; manusear artefatos de diferentes texturas, estimulando, assim, desenvolvimento do tato ${ }^{8}$. Também é essencial o estímulo ao sentido da audição que é responsável por cerca de $75 \%$ das impressões sensórias percebidas pelo cérebro de uma pessoa cega ${ }^{14}$.

Observar tais aspectos deste sistema facilita extremamente a interação do cego com os microcomputadores, e pode tornar o diálogo usuário-tecnologia simples e acessível ${ }^{9}$, não somente no relacionado a uma acessibilidade física, mas também quanto às características da própria máquina, excluindo, na medida do possível, os termos técnicos, muitas vezes só compreendidos por profissionais da área da informática. Portanto, o sistema Dosvox, segundo um dos seus principais idealizadores, é extremamente acessível e favorável à clientela cega.

\section{0 que você teria a acrescentar ao texto?}

Aqueles que mencionaram a necessidade de acrescentar algo ao texto sugeriram incluir depoimentos de familiares de usuários e/ou ex-usuários dependentes para dar um tom ainda mais real ao diálogo proposto pelo texto. Conforme consideram, o ambiente familiar vai muito além do lugar de criação e desenvolvimento inicial do ser humano, e é favorável ao compartilhamento de todas as experiências dos seus membros constituintes. Portanto, neste contexto, pode ser incluído o uso de drogas pelos filhos, por exemplo.

Apenas depoimentos de familias que têm dependentes. (P1) No texto, nada, tá completo. (P4)

[...] não tenho a acrescentar, eu fiz foi aprender com o texto. (P5)

No contexto do processo de criação e crescimento, os pais, quando detentores de sólidos valores, abertos ao diálogo e cuidadores dos seus filhos em todos os aspectos (pessoal, afetivo e espiritual), Ihes proporcionam concretas oportunidades de um desenvolvimento saudável e distanciado de práticas pouco aconselháveis, tais como o uso de substâncias químicas. Desse modo, dentro da proposta de prevenção ao uso de drogas, trabalhar a família e estimular a valorização da sua importância deve ser uma das suas diretrizes mais relevantes ${ }^{15}$.

\section{0 que você teria a retirar do texto?}

Os participantes apontaram que todos os pontos do texto tiveram profundo significado. Por conseguinte, não lhes pareceu necessário excluir nada. Uma voz discordante sugeriu resumir a parte referente a conselhos familiares e sociais em geral para explorar mais detalhadamente as drogas em si e seus efeitos relacionados.

Se eu fosse dar nota, eu daria nota 10. Ele está completo, completíssimo. (P1)

\section{[...] era só diminuir mais essa parte social. (P2) \\ [...] não retiraria nada. (P3)}

Apesar desta opinião contrária, sabe-se que, em uma família onde há um dependente químico, esta problemática afeta diretamente todos os seus membros e torna-se a maior dificuldade a ser superada neste ambiente. Fatores como violência física e verbal, dificuldades financeiras, desgaste emocional, frustração, entre outros, são freqüentes neste contexto. Entretanto, mesmo diante desta problemática, são raras as famílias que procuram ajuda e apoio psicossocial. Logo, de acordo com o exposto, não se pode dissociar a problemática droga das repercussões que esta causa, inclusive em âmbito familiar ${ }^{16}$.

\section{Qual sua opinião sobre a educação em saúde utilizando o Dosvox?}

A idéia de utilizar o Dosvox, que teoricamente é um meio de ampla divulgação, foi considerada criativa e merece ser mais explorada. Porém, conforme se observou no discurso dos cegos, também entre eles há dificuldades de acesso mais direto ao computador, pois este ainda é um meio considerado de elite, não acessível a todos. Assim, é preciso trabalhar a questão da inclusão digital entre eles. Por isso mesmo, outros meios, além do Dosvox, são sugeridos.

[...] é muito importante. Não que seja só no Dosvox, mas também em CD, tipo assim DVD, porque nem todo mundo tem acesso ao Dosvox. (P1)

[...] é bom porque a droga pode surgir não só no meio das pessoas que enxergam, mas no meio dos deficientes também. Porque os deficientes não são aqueles coitadinhos que o pessoal fala, então eu acho ótimo essa informação chegar até a gente, através do Dosvox. (P3)

[...] foi uma idéia boa, interessante, porque a gente tá ouvindo um $C D$ gravado, não tem como voltar aquela coisa que você quer, tem que voltar uma faixa inteira do $C D$, e no Dosvox você escolhe só uma linha, pra ver o que você não entendeu. Eé uma coisa boa pra nós que estamos usando realmente o computador, como qualquer outra pessoa dita normal o usaria e voltaria pra aquela palavra, sem esse tipo de dificuldade de compreender a leitura. É uma coisa muito válida que eu achei esse uso do Dosvox. (P5)

As tecnologias assistivas possuem diversas categorias que variam de acordo com a sua utilidade e com o tipo de deficiência com a qual se dispõe a trabalhar. A tecnologia trabalhada neste estudo, com o texto Drogas: Reflexão para prevenção no Sistema Operacional Dosvox, classifica-se, respectivamente, em Auxílio para cegos e Recursos de acessibilidade ao computador ${ }^{17}$.

Entretanto, existem limitações aos meios digitais de inclusão, sobretudo ao Dosvox, ferramenta com a qual se trabalhou neste projeto. Como ressaltado nos relatos de alguns 
participantes, a questão da utilização do computador e da internet como meio de educação em saúde à clientela com limitações visuais encontra dificuldades para a plena realização em virtude de alguns fatores, tais como: avanços tecnológicos nacionais nesta área são ainda muito precários em relação a outros países, e, no Brasil, o computador é um artefato relativamente caro, ou seja, nem sempre viável financeiramente aos cegos; e nas instituições de apoio e/ou ensino a estes, não são disponibilizados recursos de forma satisfatória a ponto de se dominar o uso desta tecnologia ${ }^{18}$.

Apesar dessas limitações, boa parte dos freqüentadores da ACEC tem habilidade com o programa Dosvox e necessita apenas de aprimoramentos. Desta forma, como se pode concluir, a utilização deste recurso na educação em saúde para a prevenção ao uso de drogas é válida, fato confirmado pelos depoimentos favoráveis a esta metodologia de trabalho. Contudo, nesta avaliação, devem-se considerar também as preferências pessoais, tendentes, muitas vezes, a selecionar um tipo de recurso com o qual já se está habituado, em detrimento de outra tecnologia nova que exige investimento e esforço pessoal para dominá-la.

\section{CONSIDERAÇÕES FINAIS}

De acordo com o exposto, foi criada e avaliada a Tecnologia Assistiva em Saúde constituída pelo texto educativo Drogas:

\section{Referências}

1.Ministério da Saúde (BR). Normas e procedimentos na abordagem do abuso de drogas. Brasília (DF); 1991.

2. Aratangy LR. 0 desafio da prevenção. In: Aquino JG, organizador. Drogas na escola: alternativas teóricas e práticas. São Paulo (SP): Summus; 1998.

3. Cezario KG, Pagliuca LMF. 0 comportamento de cegos diante das drogas: uma questão de saúde. [monografia de graduação]. Fortaleza (CE): Departamento de Enfermagem/UFC; 2007.

4. Costa EM, Castro DN, Pagliuca LMF. Assistência de enfermagem: percepção da pessoa cega-reflexão sobre ética e solidariedade. Rev Bras Enferm 1999 out/dez; 52(4): 615-23.

5. Pillon SC, Luis MAV. Modelos explicativos para o uso de álcool e drogas e a prática da enfermagem. Rev Latino-am Enfermagem [periódico on line]. 2004 jul/ago; [citado 02 abr 2007]; 12(4): [aprox. 8 telas]. Disponível em: http://mww.scielo.br. 6. Bersch R. Introdução à tecnologia assistiva [on line] 2005; [citado 08 out 2007]; [aprox. 17 telas]. Disponível em: http://wnw.cedionline.com.br/artigo_ta.html .

7. Pagliuca LMF, Costa EM, Costa NM. Desenvolvendo tecnologia para prevenção e tratamento de emergências domésticas para cegos. Rev Bras Enferm 1996 jan/mar; 49(1): 83-104.

8. Cerqueira JB, Ferreira EMB. Recursos didáticos na educação especial. Benjamim Constant [periódico on line] 2000 abr; [citado 2 abr 2007]; (15): [aprox. 8 telas]. Disponível em: http://200.156.28.7/Nucleus/media/ common/Nossos_Meios_RBC_RevDez1996_Artigo3.doc.

9. Borges JA. Dosvox: um novo acesso dos cegos à cultura e ao trabalho. Benjamim Constant [periódico on line] 1996 maio [citado 23 mar 2007]; (3): [aprox. 7 telas]. Disponível em: http://200.156.28.7/Nucleus/media/ common/Nossos_Meios_RBC_RevMai1996_Artigo5.doc.

10. Polit DF, Hungler BP. Fundamentos de pesquisa em enfermagem. Tradução de Regina Machado Garcez. $3^{\text {a }}$ ed. Porto Alegre (RS): Artes Médicas; 1995.
Reflexão para prevenção. A tecnologia apoiou-se na estratégia de utilizar o programa sintetizador de voz Dosvox como meio acessível aos cegos para que estes pudessem, ao manusear livremente o computador, receber informações gerais e em todos os aspectos sobre a problemática droga, via texto reflexivo e dialogal que proporcionou o esclarecimento sobre os pontos mais relevantes da temática.

Todavia, para a clientela escolher livremente, todos os meios de Tecnologia Assistiva devem estar disponíveis, permitindoIhe, assim, optar conforme as suas preferências. Dentro desse universo de possibilidades, que auxiliam no processo de educação em saúde, o recurso Drogas: Reflexão para prevenção, disponibilizado no Dosvox, foi avaliado pelo cego como adequado. Tal afirmativa é corroborada pelos depoimentos dos entrevistados.

Ações como esta reforçam o papel do enfermeiro como educador em saúde comprometido com a promoção do bemestar e da autonomia de sua clientela. 0 trabalho foi extremamente gratificante pelo crescimento profissional e pessoal propiciado, como geração de conhecimento, superação de limites e reflexões éticas. É responsabilidade dos profissionais de saúde o cuidado em saúde mental de toda a população. Portanto, as demandas da clientela possuidora de necessidades especiais não podem ser negadas, sobretudo as dos cegos.

11. Estabel LB, Moro ELS, Santarosa LMC. A inclusão social e digital de pessoas com limitação visual e o uso das tecnologias de informação e de comunicação na produção de página para a Internet. Ci. Inf. [on line] 2006 jan/abr; [citado 2 mar 2007]; 35(1): [aprox. 10 telas]. Disponível em: http://www.scielo.br.

12. Spricigo JS, Alencastre MB. 0 enfermeiro de unidade de saúde e 0 usuário de drogas: um estudo em Biguaçu(SC). Rev Latino-am Enfermagem [on line] $2004 \mathrm{mar} / \mathrm{abr}$; [citado 2 abr 2007]; 12 (n.esp.): [aprox. 8 telas]. Disponivel em: http://www.scielo.br.

13. Rebello $S$, Monteiro S, Vargas E. A visão de escolares sobre drogas no uso de um jogo educativo. Interface - comunicação, saúde, educação [periódico on line] $2001 \mathrm{mar}$; [citado $23 \mathrm{mar} 2007$ ]; 5(8): [aprox. 14 telas]. Disponivel em: http://www.interface.org.br/ingles/revista8/artigo1.pdf.

14. Oliveira JV. Do essencial invisível: arte e beleza entre os cegos. Rio de Janeiro (RJ): Ed. Revan/FAPERJ; 2002.

15. Schenker M, Minayo MCS. Fatores de risco e de proteção para o uso de drogas na adolescência. Cienc saude colet [on line] 2005 jul/set; [citado 14 fev 2007]; 10(3): [aprox. 13 telas]. Disponivel em: http://www.scielo.br. 16. Filizola CLA, Pavarini SCL, Perón CJ, Petrilli Filho JF, Nascimento MMA. Compreendendo o alcoolismo na família. Esc Anna Nery Rev Enferm 2006 dez; 10(4): 660-70.

17. Fontana MVL,Vergara Nunes EL. Educação e inclusão de pessoas cegas: da escrita Braille à Internet. Rev FAFIBE 2006. [periódico on line]; [citado 14 fev 2007]; 2: [aprox. 6 telas]. Disponível em: http://www.fafibe.br/revistaonline/ arquivos/marcusfontana_educacaoeinclusaodepessoascegas.pdf.

18. Bersch R, Tonolli JC. Tecnologia assistiva [on line] 2007; [citado 08 out 2007]; [aprox. 10 telas]. Disponivel em: http://www.assistiva.com.br.

\section{Nota}

aExtraído de monografia de graduação em Enfermagem "0 comportamento de cegos diante das drogas: uma questão de saúde". Projeto financiado pelo CNPq. 